Military Technical College Kobry El-Kobbah Cairo, Egypt

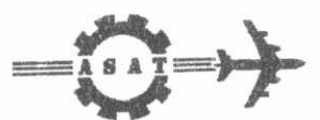

$10^{\text {th }}$ International Conference

On Aerospace Sciences\&

Aviation Technology

\title{
EFFECT OF POST-CHAMBER ON COMBUSTION EFFICIENCY IN HYBRID ROCKET MOTORS
}

\author{
A. Makled* A-N. Zayed* H. Abdalla* M. El-Senbawi*
}

\section{ABSTRACT}

In recent years hybrid propulsion has attracted widespread attention in view of a number of potentially attractive features, which could combine the advantages of both liquid and solid rocket motors. This article compares the characteristics of the hybrid propulsion system with those of solid and liquid propulsion systems. Because of the low combustion efficiency of the hybrid systems, the enhancement of the hybrid combustion efficiency, by means of the post-combustion chamber, is investigated theoretically and experimentally.

KEY WORDS: Rocket motor, Hybrid propulsion, Regression rate

\section{NOMENCLATURE}

$\begin{array}{ll}\text { A } & \text { area } \\ C^{*} & \text { characteistic velocity } \\ \text { d } & \text { diameter } \\ \text { D } & \text { grain outer diameter } \\ \text { F } & \text { motor thrust } \\ G & \text { mass flux } \\ \mathrm{I}_{\mathrm{s}} & \text { specific impulse } \\ \mathrm{L}_{\mathrm{fu}} & \text { grain length } \\ \mathrm{L}^{*} & \text { characteristic length } \\ \mathrm{m} & \text { mass flow rate } \\ \mathrm{P} & \text { pressure } \\ \mathrm{r} & \text { regression rate }\end{array}$

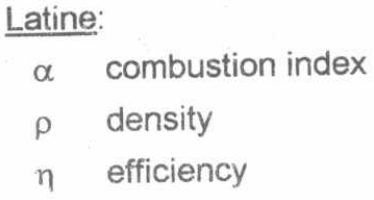

Subscript:

c combustion
fu fuel
ox oxidizer
po port
th throat
tot total

* Egyptian Armed Forces 


\section{INTRODUCTION}

This article compares hybrid propulsion systems with those of solid and liquid propulsion systems. In the hybrid systems, the combustion chamber contains only the solid fuel, while the liquid oxidizer is stored in a tank and injected through a feeding system into a channel inside the solid fuel charge. The combustion of the hybrid system may be controlled by means of controlling the feeding of the liquid oxidizer. In solid rocket motors, it is extremely difficult to stop, restart, or control the combustion after igniting the rocket motor. In liquid propellant rocket motors, the control of combustion occurs with loss of simplicity. Consequently, the comprehensive properties of controllability, flexibility, and safety make the hybrid rocket system very promising propulsion system for use in future military and space missions.

The constructions of three different hybrid propulsion systems are illustrated and explained to investigate the difference between those constructions. A detailed explanation, of the combustion process in a hybrid motor, is presented with illustration of the boundary layer, the temperature distribution, and the velocity performance of the combustion gases. The combustion efficiency, of a hybrid propulsion system, has been defined to be used as a judgement for the performance of the propulsion systern. An experimental investigation is presented on three implemented hybrid systems to study the effect of the post-chamber on the combustion efficiency.

\section{COMPARISON BETWEEN SOLID, LIQUID, AND HYBRID SYSTEMS}

A liquid rocket motor consists of a fuel tank, oxidizer tank, feeding system, controiling system, and a combustion chamber integrated with a nozzle. The liquid fuel and oxidizer are injected through an injection head into the combustion chamber where the liquid fuel and oxidizer are self-ignited when they are attached at the first third of the combustion chamber, as shown in Fig. 1a. The complete combustion zone takes place at the last third of the combustion chamber.

A solid propeliant rocket motor consists of a combustion chamber and a nozzle, as shown in Fig. 1b. the chamber contains a solid propellant grain composed of fuel, oxidizer, and other additives. The combustion is started with an igniter to start burning on all exposed surfaces of the grain. The gas phase combustion zone occurs within an order of millimeters from the propellant surface with only active metal droplet combustion that occurs in the port or the nozzle.

A hybrid rocket motor looks like a combination of a liquid and a solid rocket motors The hybrid propulsion system borrows the oxidizer tank, feeding system, and the injection process from the liquid system. Also, it borrows the solid grin, motor casing, and nozzle hardware from the solid system. The combustion starts automatically when the liquid oxidizer is injected, through the injection head, to contact the exposed surfaces of the solid fuel grain. The complete combustion zone varies along the path through the solid grain, as shown in Fig. 1c. 
Table 1 represents a comparison between the solid propellant rocket motor, liquid propellant rocket motor; and hybrid rocket motor on the properties that characterize the performance of each.

Table 1 Comparison between the solid, liquid, and hybrid systems

\begin{tabular}{|l|c|c|c|}
\hline & SPRM & LPRM & HRM \\
\hline Specific impulse & $180-300$ & $140-460$ & $290-380$ \\
\hline Sliver & $1-6 \%$ & None & $1-6 \%$ \\
\hline Thrust controllability & Low & High & High \\
\hline Combustion efficiency & $95-97 \%$ & $98-99 \%$ & $83-91 \%$ \\
\hline Propellant density & High & Low & Acceptable \\
\hline Nozzle erosion & Low & None & High \\
\hline Grain crack effects & High & None & Low \\
\hline
\end{tabular}

\section{CONSTRUCTION OF HYBRID SYSTEMS}

There are three different constructions of the hybrid propulsion systems, namely, classical, inverse, and tribrid hybrid propulsion systems as shown in Fig. 2.

The classical hybrid system has a solid fuel grain burnt with liquid oxidizer. It is the common used hybrid propulsion system, as shown in Fig. 2a. Therefore, it is the subject of this paper.

The inverse hybrid system has a solid oxidizer grain used for burning the liquid fuel, as shown in Fig. 2b. Here, the combustion chamber has a relatively greater size because of the requirement of greater amount of oxidizer.

In the tribrid hybrid system, the combustion chamber contains a solid grain of a fuel rich propellant. The system includes a main liquid oxidizer and a support gaseous oxidizer. The support oxidizer can be branched from the main stream or from compressed gas feeding system to be injected into the post-combustion chamber (aft-combustion chamber). This type, of hybrid system, is used to increase the efficiency of combustion or to attain a constant mixing ratio and operating pressure. It also permits to modify the thrust with greater controllability.

\section{HYBRID COMBUSTION PROCESS}

The burning mechanism of hybrid rocket motors has been the subject of numerous theoretical investigations $[2,4,5]$. The combustion process, in a hybrid propulsion system, differs very essentially from that of a solid or a liquid system, as illustrated in Fig. 1. In the hybrid combustion, a boundary layer is formed above the surface of the 
fuel grain. This boundary layer is fed by the oxidizer entering from the side of the channel axis and by gasified fuel. In the steady state, the oxidizer dropiets become heated as they pass through the boundary layer and tend to evaporate due to the existance of the flame zone (high temperature) above the premixed reaction zone, as shown in Fig. 3.

Fuel is partly decomposed and evaporated (gasified) at the solid surface due to the convective (or convective plus radiative) heat transfer; then the fuel particles diffuse toward the centerline of the combustion volume. Mutually, the gaseous oxidizer diffuses outward from the centerline through the turbulent boundary layer. At a point, where the ratio of oxidizer to fuel (O/F ratio) us somewhat fuel-rich, combustion occurs in a layer whose thickness is about $10 \%$ of the boundary layer. As shown in Fig. 3 , the flame position is substantially closer to the fuel surface than the edge of the boundary layer.

The surface regression occurs in a direction perpendicular to the burnt surface. The main parameters affecting the regression rate are the total propellant mass flux " $\mathrm{G}_{\mathrm{tot}}$ " and the combustion chamber pressure " $p_{c}$ "[6]. Other parameters such as the temperature of the fuel grain and the mixing ratio have only a slight effect. The general formula of the regression rate law is given in [6] as,

$$
r_{f u}=a p_{c}^{\alpha} G_{o x}^{n}
$$

Sometimes the oxidizer mass flux is replaced by the total mass flux where

$$
\begin{aligned}
G_{t o t} & =G_{o x}+G_{f u} \\
G_{o x} & =\frac{4 \dot{m}_{o x}}{\pi d_{p o}^{2}} \\
G_{f u}(x) & =4 \rho_{f u} \int_{0}^{x} \frac{r_{f u}(x)}{d_{p o}(x)} d x
\end{aligned}
$$

Equation (4) shows that the fuel flux " $\mathrm{G}_{\mathrm{fu}}$ " varies along the $\mathrm{x}$ direction.

The regression behavior of a fuel grain (in a hybrid system) differs from that of a solid propellant grain because of the combustion mechanism [7] as presented in Table 2. 
Table 2 Regression behavior of solid and hybrid systems

\begin{tabular}{|l|l|l|}
\hline \multicolumn{1}{|c|}{ Comparison item } & \multicolumn{1}{|c|}{ Solid rocket motor } & \multicolumn{1}{|c|}{ Hybrid rocket motor } \\
\hline $\begin{array}{l}\text { Combustion mechanism } \\
\text { dorninated by }\end{array}$ & - Chemical kinetics & - Heat transfer \\
\hline $\begin{array}{l}\text { Main parameter governing } \\
\text { regression }\end{array}$ & $\begin{array}{l}\text { - Combustion chamber } \\
\text { pressure }\end{array}$ & - Oxidizer mass flux \\
\hline $\begin{array}{l}\text { Main parameters governing } \\
\text { operating point }\end{array}$ & $\begin{array}{l}\text { - Combustion chamber } \\
\text { pressure }\end{array}$ & $\begin{array}{l}\text { - Oxidizer mass flow rate } \\
\text { burning area / port area } \\
\text { grain }\end{array}$ \\
\hline $\begin{array}{l}\text { Regression rate influenced } \\
\text { by }\end{array}$ & $\begin{array}{l}\text { - Combustion temperature } \\
\text { - Particle size of oxidizer } \\
\text { - Propellant composition } \\
\text { - Initial grain temperature } \\
\text { - Gas velocity } \\
\text { - Propellant configuration }\end{array}$ & $\begin{array}{l}\text { - Composition of solid fuel } \\
\text { grain. } \\
\text { Melting point. } \\
\text { - Flame temperature } \\
\text { Combustion chamber } \\
\text { pressure. }\end{array}$ \\
\hline
\end{tabular}

\section{COMBUSTION EFFICIENCY}

The combustion efficiency " $\eta_{c}$ ", of a hybrid rocket motor, can be expressed as a ration between the average experimental characteristic velocity and the theoretical value.

$$
\eta_{\mathrm{c}}=\frac{\mathrm{c}_{\mathrm{exp}}^{*}}{\mathrm{c}_{\mathrm{th}}^{*}}
$$

The average experimental value of $c^{*}$ is obtained as

$$
c_{\text {exp }}^{*}=\frac{p_{c} A_{t h}}{\dot{m}_{\text {tot }}}
$$

where the total mass flow rate is defined as

$$
\dot{\mathrm{m}}_{\mathrm{tot}}=\dot{\mathrm{m}}_{\mathrm{ox}}+\dot{\mathrm{m}}_{\mathrm{fu}}
$$

The theoretical value of $c^{*}$ is calculated according to the used fuel and oxidizer by means of a thermo-chemistry code [9] for equilibrium combustion as a function of pressure, equivalence ratio, and reactant composition. 

In general, high combustion efficiency can lead to one or more of the following
advantages:

- Reduce emissions of combustion gases (soot, under-burned hydrocarbons).

- Reduce flame length and thereby smaller safety surrounding area.

- Improve the combustion stability.

- Increase nozzle life.

\section{POST-COMBUSTION CHAMBER}

The post, aft-mixing or reaction, combustion chamber is located at the lower end of the solid propellant grain just behind the nozzle (see Fig. 4) to improve the mixing between fuel and oxidizer, and to insure completion of the chemical reaction within the motor. To enhance mixing, designers may undertake one or more of the following
options:

- Add post-combustion chamber to the motor.

- Provide a physical mixing surface by using turbulent diaphragm (vortex generator).

- Inject more oxidizer at the end of the combustion chamber (secondary injector).

- Use a submerged nozzle.

Optimum design, of the post-chamber in a hybrid motor, will require a fundarnental understanding of the flow and combustion processes. Particular interest is the capability to predict flow and combustion phenomenon through the active channel, solid-grain port, post-chamber, and the nozzle. As shown in Table 1, the combustion efficiency, in hybrid systems, is lower than that in solid and liquid systems due to poor mixing of the fuel and oxidizer. This is because combustion occurs only in a flame layer located well away from the grain surface. Some (about 15\%), of the vaporized fuel leaving the grain, is convicted downstream under the flame and is not oxidized.

Also, the flame zone tends to be fuel-rich, the local oxidizer/fuel (O/F) ratios are very close to the stoichiometric values. These characteristics of combustion require that mixing occur downstream of the grain and ahead of the nozzle. Combined with a possible need for adding oxidizer at the aft-end caused by throttling, makes it necessary tp provide suitable combustion volume (post-chamber) prior to expansion.

In this study, an aft-mixing method was used; which proved a success in improving the combustion efficiency for a wide range of operating conditions. The concept was to improve and maximize the mixing of oxidizer and fuel or to minimize the amount of consumed propellant that is not transferred to energy. 
As shown in Fig. 3 and 4, the active channel, through the fuel grain length, is not enough to complete mixing and combustion of oxidizer and fuel. To permit more mixing, it is required to add a post-chamber which acts as a vortex generator; but this addition may lead to remarkable increase in the motor length. To minimize the increased length of the post-chamber, an additional element (mixing disc) is inserted to ensure adequate mixing of gas stream and thus lead to an almost complete reaction within the chamber and before the nozzle. Unfortunately, the insertion of a mixing disc creates a pressure drop.

\section{SECONDARY INJECTION AT POST-CHAMBER}

A part of oxidizer may be injected at the post-chamber. It is important to examine the sensitivity of the combustion pressure and mixing ratio to the aft-combustion injection. Indeed, modulation of thrust while keeping a constant mixing ratio is a desirable goal for efficient performance [10].

As shown in Eq. (1), the regression rate of a solid fuel grain varies with the oxidizer mass flux. However, the oxidizer mass flow is the only adjustable parameter of a hybrid motor resulting from a throttling operation. It follows from Eq. (1) that changes in oxidizer mass flux " $G_{o x}$ " strongly affect the overall mixture ratio, and hence the thrust. For better understanding, consider a grain with a single cylindrical port diameter " $\mathrm{dpo}_{\mathrm{po}}$ and length " $\mathrm{L}$ ". The oxidizer and fuel mass flow rates are expressed as:

$$
\begin{aligned}
& \dot{\mathrm{m}}_{\mathrm{ox}}=\frac{\pi}{4} \mathrm{~d}_{\mathrm{po}}^{2} \mathrm{G}_{\mathrm{ox}} \\
& \dot{\mathrm{m}}_{\mathrm{fu}}=\pi \mathrm{d}_{\mathrm{po}} L \rho_{\mathrm{fu}} \mathrm{r}_{\mathrm{fu}}
\end{aligned}
$$

Substituting $\mathrm{r}_{\mathrm{fu}}$ from Eq. (1),

$$
\dot{\mathrm{m}}_{\mathrm{fu}}=\text { const } \times \mathrm{d}_{\mathrm{po}}^{1-2 \mathrm{n}} \dot{\mathrm{m}}_{\mathrm{ox}}^{\mathrm{n}}
$$

The value of $n$ ranges from 0.4 to 1.0 [2], and Eq. (10) is simplified by taking $n=0.5$ :

$$
\dot{\mathrm{m}}_{\mathrm{fu}}=\text { const } \times \dot{\mathrm{m}}_{\mathrm{ox}}^{0.5}
$$

For example, let us examine how to reduce the thrust to 0.9 its design value. The oxidizer mass flow ( $\left.\dot{m}_{\mathrm{ox}}\right)_{\text {head }}$ is cut to 0.81 its design value $\left(\dot{m}_{\mathrm{ox}}\right)_{\text {des }}$. This will result in reducing the mass flow. The mixture will be a fuel-rich, so to restore the initial mixing ratio, a part of oxidizer is to be injected at the post-chamber $\left(\dot{m}_{o x}\right)_{\text {post }}$ (downstream of the grain). In this case, it is required to inject 0.09 of the design value of the oxidizer mass flow to maintain the initial mixing ratio and complete the oxidation of the excess fuel. In this manner, the mixing ratio is kept constant and the net oxidizer consumed 
is therefore 0.9 its design value. Hence, the thrust is reduced to the same order. Table 3 presents more extended data about the needed reduction in oxidizer corresponding to a required modulation of thrust.

Table 3 Secondary injection-throttling parameters

\begin{tabular}{|c|c|c|c|}
\hline $\begin{array}{c}\text { Required } \\
\text { decrease in } \\
\text { thrust \% }\end{array}$ & $\frac{\left(\dot{\mathrm{m}}_{\text {ox }}\right)_{\text {head }}}{\left(\dot{\mathrm{m}}_{\text {ox }}\right)_{\text {des }}}$ & $\frac{\left(\dot{\mathrm{m}}_{\text {ox }}\right)_{\text {post }}}{\left(\dot{\mathrm{m}}_{\text {ox }}\right)_{\text {des }}}$ & $\frac{\left(\dot{\mathrm{m}}_{\text {ox }}\right)_{\text {total }}}{\left(\dot{\mathrm{m}}_{\text {ox }}\right)_{\text {des }}}$ \\
\hline 0 & 1 & 0 & 1 \\
\hline 10 & 0.81 & 0.09 & 0.9 \\
\hline 20 & 0.64 & 0.16 & 0.8 \\
\hline 30 & 0.49 & 0.21 & 0.7 \\
\hline 40 & 0.36 & 0.24 & 0.6 \\
\hline 50 & 0.25 & 0.25 & 0.5 \\
\hline 60 & 0.16 & 0.24 & 0.4 \\
\hline 70 & 0.09 & 0.21 & 0.3 \\
\hline 80 & 0.04 & 0.16 & 0.2 \\
\hline 90 & 0.01 & 0.09 & 0.1 \\
\hline 100 & 0 & 0 & 0 \\
\hline
\end{tabular}

\section{EXPERIMENTAL INVESTIGATION}

The experimental work is performed to investigate the effect of the post chamber on the combustion efficiency in a hybrid system. A test scale hybrid system is implemented where the oxygen " $\mathrm{O}_{2}$ " is used as a gaseous oxidizer to be injected through a solid fuel grain of polymethyl-methacrylateor (PMMA). The grain dimensions are a port diameter of $22 \mathrm{~mm}$, outer diamter of $50 \mathrm{~mm}$, and grain length of $150 \mathrm{~mm}$. The operating time (the burning time) is about 10 seconds.

Three grains were used for three static firing tests. The first, for test (1) as shown in Fig. $5 a$, is considered as a base line with no post-chamber. The second, for test (2) as shown in Fig. $5 b$, contains a post chamber of length $50 \mathrm{~mm}(L / D=1.0)$. The third, for test (3) as shown in Fig. $5 c$, contains a post chamber of length $75 \mathrm{~mm}(\mathrm{~L} / \mathrm{D}=1.5)$.

The test rig, as illustrated in Fig. 6, consists of three main groups:

(1) Oxidizer feeding system with auxiliary elements to measure and control the required mass flow rate of oxygen as oxidizer. 
(2) The hybrid propulsion system which mainly contains:

- oxidizer inlet

- solid fuel grain

- nozzle

(3) Measurement instrumentation (test rig) [11].

Table 4 presents some of the basic measurements [12] (e.g. chamber pressure and thrust), applied measurements [12] (e.g. average mixing ratio, average regression rate, specific impulse, and experimental $\left.\mathrm{c}^{*}\right)$, and some of the calculated parameters (e.g. theoretical $\mathrm{C}^{*}$, characteristic length, combustion efficiency) for the three tests.

Table 4 Comparison of the post-chamber effects on the three motors

\begin{tabular}{|l|c|c|c|}
\hline \multicolumn{1}{|c|}{ Parameters } & $\begin{array}{c}\text { Test }(1) \\
\text { (base line) }\end{array}$ & $\begin{array}{c}\text { Test (2) } \\
(\mathrm{L} / \mathrm{D}=1.0)\end{array}$ & $\begin{array}{c}\text { Test (3) } \\
(\mathrm{L} / \mathrm{D}=1.5)\end{array}$ \\
\hline Chamber pressure [bar] & 12.2 & 12.9 & 13.3 \\
\hline Thrust [N] & 8.6 & 9.9 & 10.568 \\
\hline Average mixing ratio & 3.8 & 3.7 & 3.8 \\
\hline Average regression rate [mm/s] & 0.108 & 0.109 & 0.107 \\
\hline Experimental c* [m/s] & 1324 & 1398 & 1444 \\
\hline Theoretical c* [m/s] & 1525 & 1529 & 1525 \\
\hline Combustion efficiency \% & 87 & 91 & 95 \\
\hline Specific impulse [s] & 127.9 & 146.1 & 156.0 \\
\hline Characteristic length [m] & 7.5 & 20.6 & 27.1 \\
\hline
\end{tabular}

According to the burning mechanism, see Fig. 3, it was observed on the solid fuel grains (after combustion, as shown in Fig. 8) that the post-chamber decreases the ablation in the immediate vicinity of injector, as injection becomes more and more radial. Figure 7(a) shows the ablation occurred in test (1) where there is no postchamber, and Fig. 7(b) shows the effect of the post-chamber of decreasing the ablation of inner duct of the solid fuel grain in test (2). This statement needs more experimental work to obtain the required explanation of this observation but it is included in this paper.

\section{CONCLUSIONS}

To achieve high efficiency of a hybrid system, the post combustion chamber, or secondary injection may be employed. The thrust modulation is the main attraction of hybrid propulsion. It can be carried out more easily than other propulsion system. When operating at off-design conditions regarding the oxidizer flow rate, appreciable performance loss is likely to occur. This gives rise to limitation in the throttling range 
of oxidizer mass flow rate. The solution is achievable through using a secondary oxidizer injection at post combustion chamber besides the head injection. The increased combustion efficiency is clearly demonstrated as revealed by the shown experimentally investigated cases. However, the attainable better performance might have an influence on the simplicity of the system.

\section{REFERENCES}

[1] Goldberg, B. and Cook, J., "Preliminary Result of NASA / Industry Hybrid Propulsion Program", AIAA-92-3299, July 1992.

[2] Humble, R., Henery Gray, N., and Larson, W. J., "Propulsion System Analysis and Design", Report of the United State Air Force Academy, 1995.

[3] Makled, A., "Design Optimization of Solid Propellant Rocket Motors", MSc. Thesis, MTC, Cairo 1994.

[4] Maruman, G., et al, "Fundamentals of Hybrid Boundary Layer Combustion", Progress in Astronauts \& Aeronautics, Heterogeneous Combustion, Academic Press, Vol. 15, pp. 485-522, 1964

[5] Maruman, G., "Combustion in the Turbulent Boundary Layer on a Vaporizing Surface", Tenth International Symposium on Combustion, 1965.

[6] Miller, E., "Hybrid Rocket Combustion Regression Rate Model", AIAA Journal, Vol. 4, pp. 752-753, May 1966.

[7] Kosdon, FR. J. and Williams, F. A., "Pressure Dependence of Non-Metabolized Hybrid Fuel Regression Rate", AIAA Journal, Vol. 5, pp. 774-778, 1970.

[8] Sutton, G. P., "Rocket Propulsion Elements", 6-th Edition, ISBN 0-471-52938-9, John Wiley, 1992.

[9] Curt Self, "Computer Program for Calculation of Complex Chemical Equilibrium Combustion", NASA SP-273, US. Air Force Academy, Version 15 July 1994.

[10] Loh, W. H. T., "Jet, Rocket, Nuclear, lon, and Electric Propulsion: Theory and Design", Spring-Verlag, New York, 1968.

[11] Zayed, A-N. and Lawton, B., "Methods of Measuring the Burning Rate in Solid Rockets by Using a Computed Tomography System", AIAA Paper 95-2594, 30-th AIAA Joint Propulsion Conference, San Diago, July 1995.

[12] Zayed, A-N., "Rocket Testing", MTC Printed Lecture, 2002. 


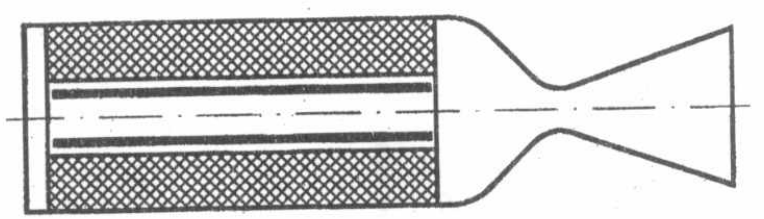

(a) Solid rocket motor
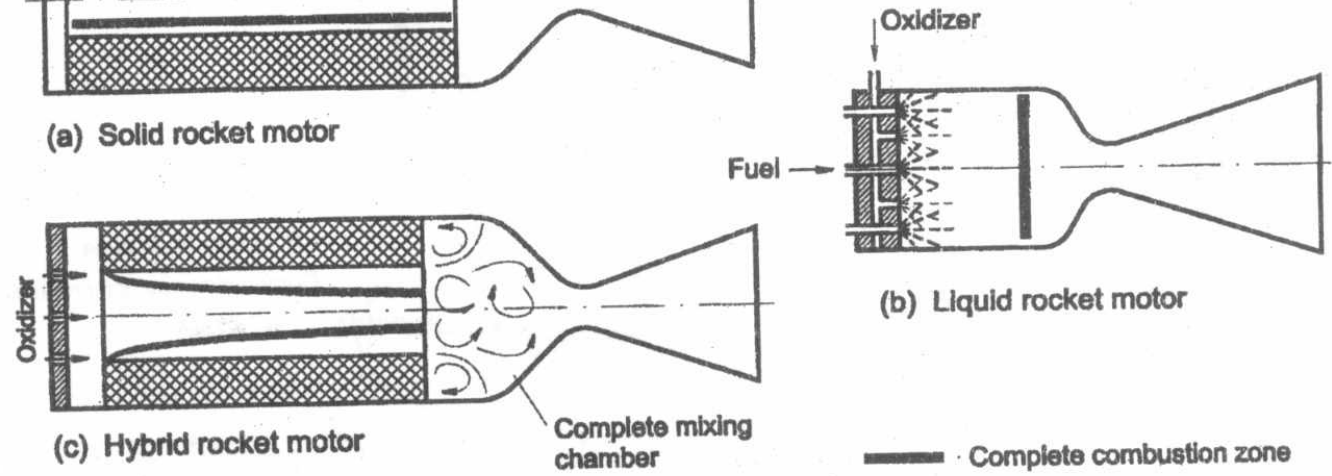

(b) Llquid rocket motor

Fig. 1 Combustion in solid, liquid, and hybrid systems

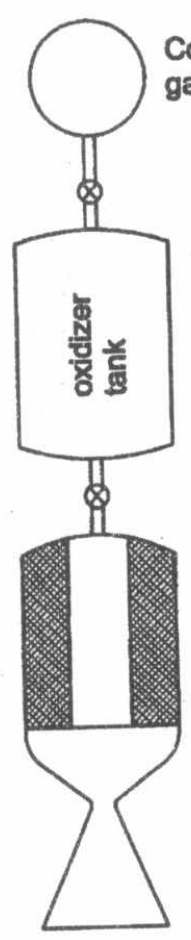

(a) Classical hybrid system

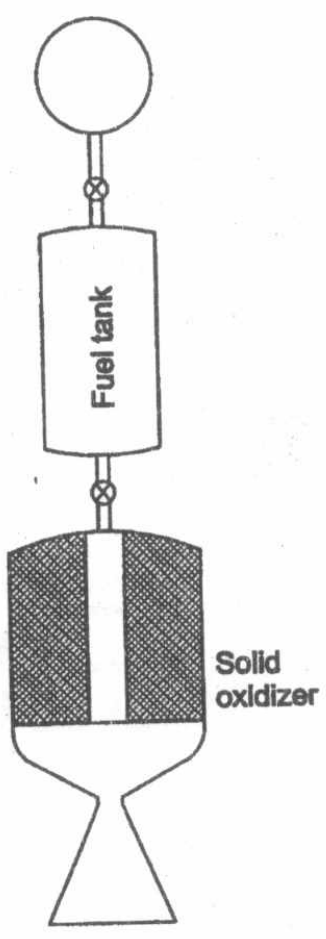

(b) Inverse hybrid system

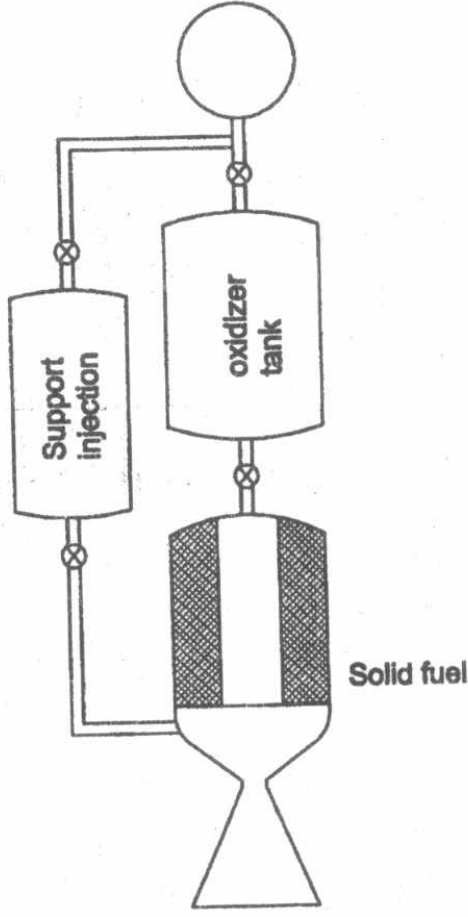

(c) Tribrid hybrid system

Fig. 2 Schemes of hybrid propulsion systems 


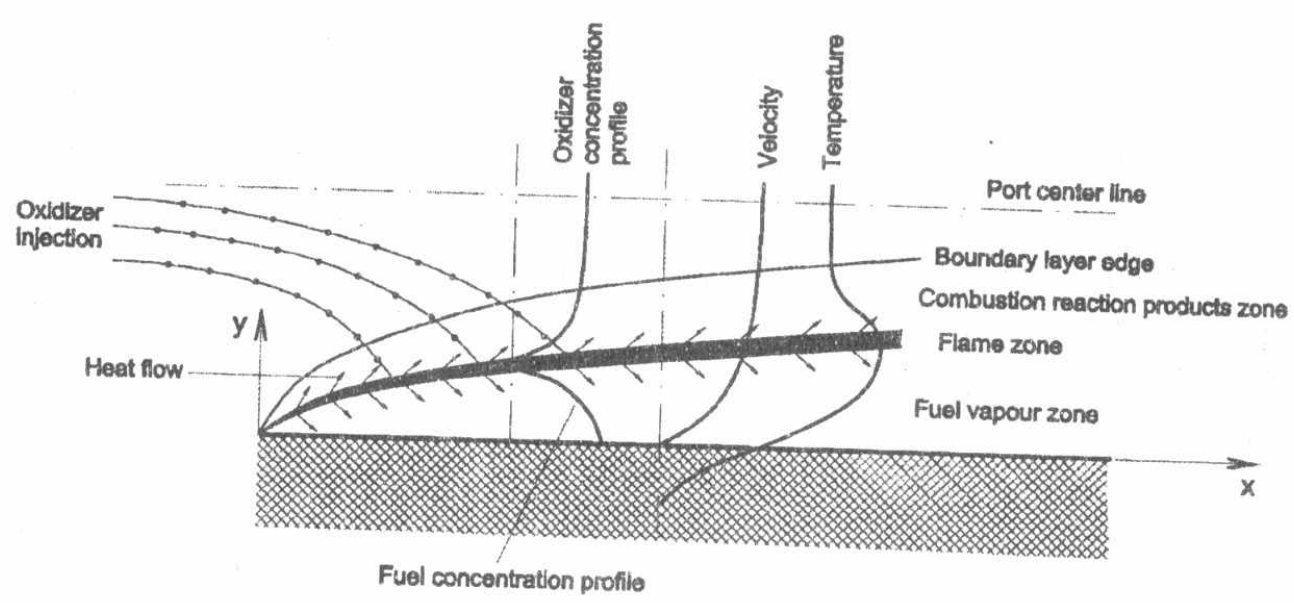

Fig. 3 Simplified model of hybrid motor combustion process

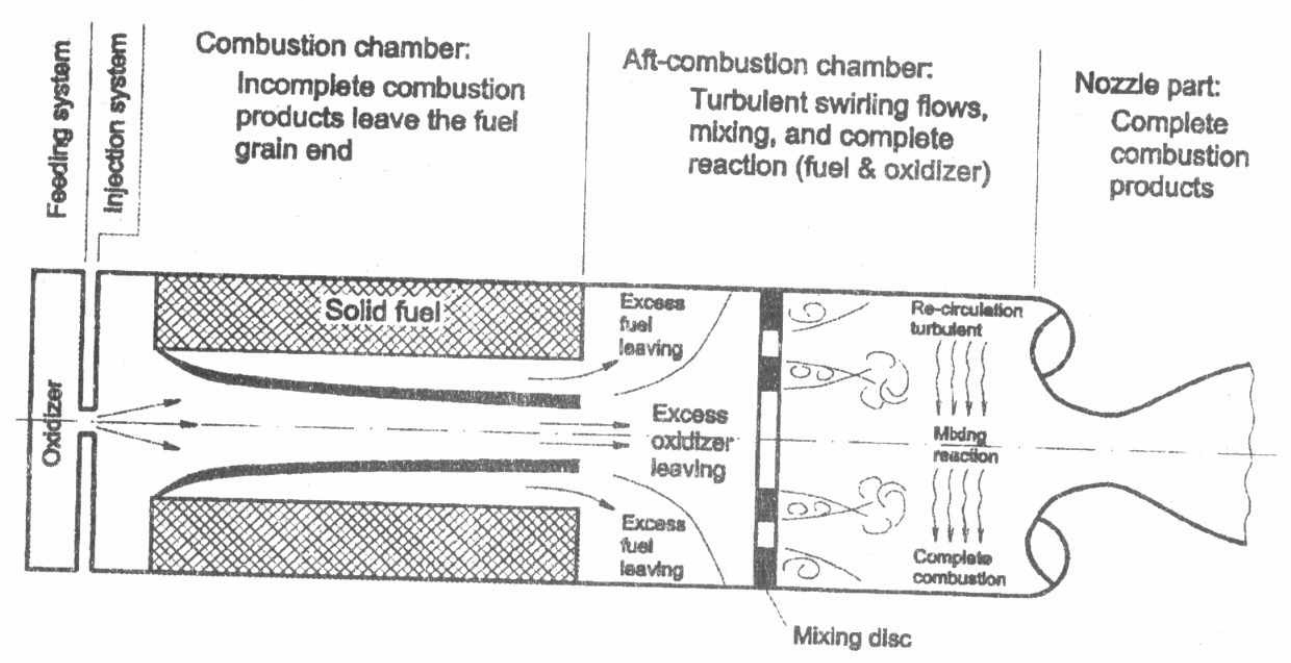

Fig. 4 Schematic layout of a hybrid motor 

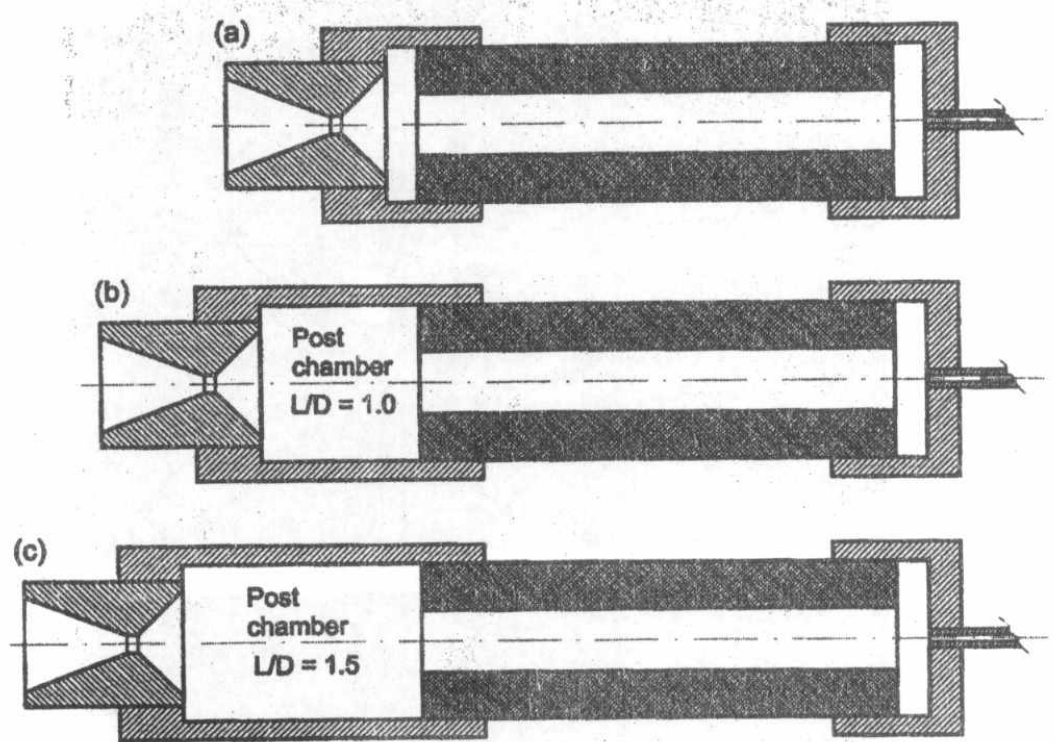

Fig. 5 The three tested motors with different post-chambers

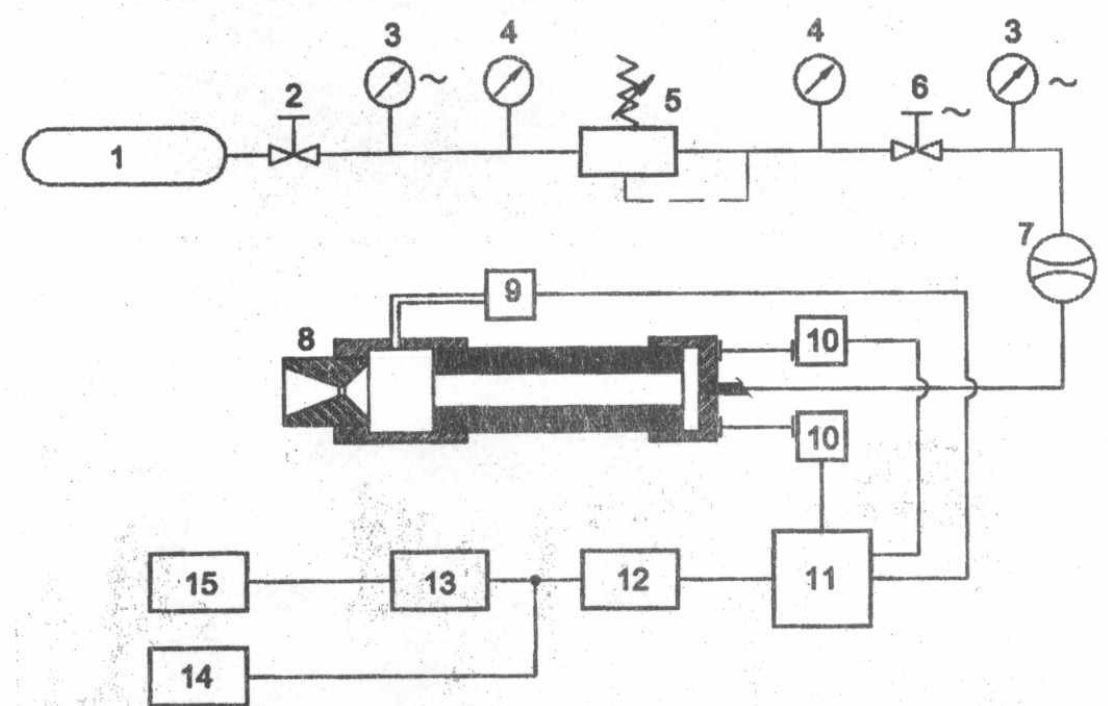

1- Compressed oxygen tank

2- Needle valve

3- Pressure indicator

4- Pressúre gauge

5- Pressure regulator
6- On/Off valve

7- Flow-meter

8- Hybrid rocket motor

9- Pressure transducer

10- Thrust transducer
11- Amplifier

12- Low-pass filter 13- AVD converter

14- UV plotter

15- Personal computer

Fig. 6 Scheme of the test rig of a hybrid rocket motor 
Proceedings of the 10 $10^{\text {th }}$ ASAT Conference, 13-15 May 2003
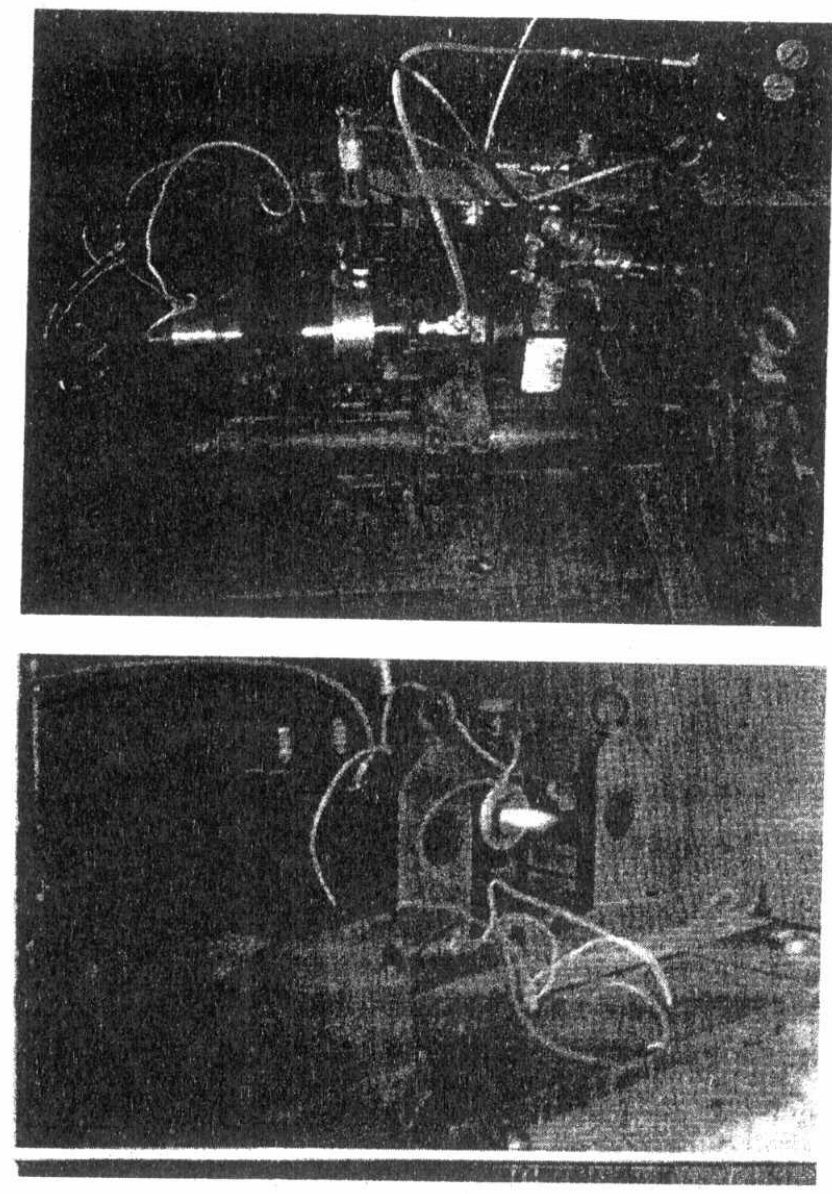

Fig. 7 Installation of a hybrid rocket motor on a test stand

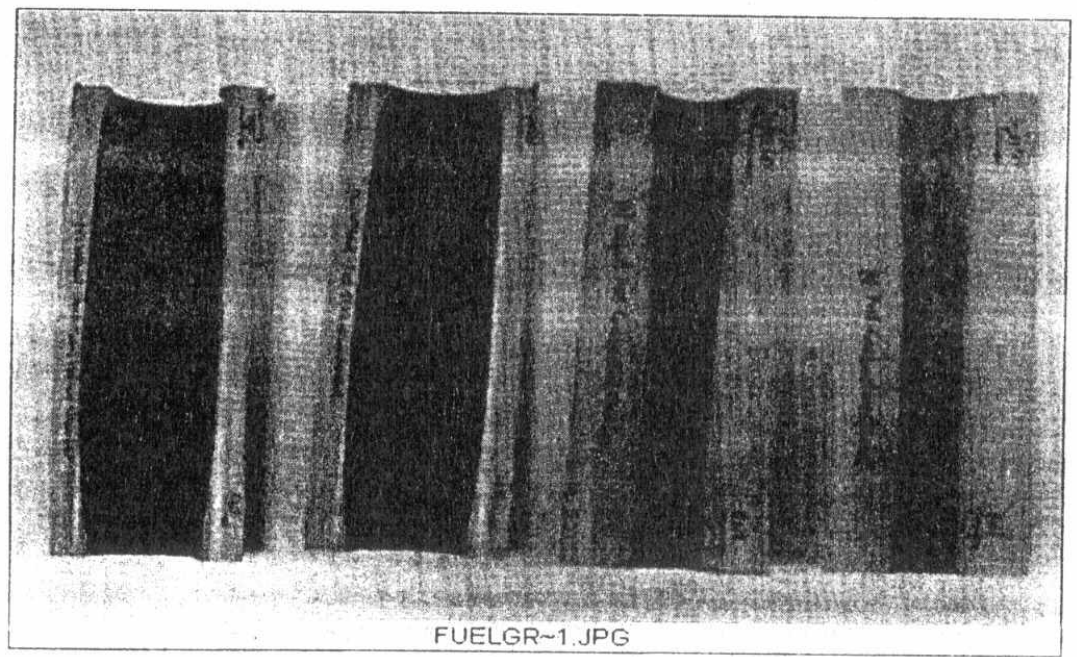

Fig. 8 Photography of cross-section of the solid fuel grain after combustion 